\title{
Primary bronchopulmonary amyloid tumour with massive hilar lymphadenopathy
}

\author{
PJ THOMPSON, J JEWKES, B CORRIN, KM CITRON \\ From the Cardiothoracic Institute and Brompton Hospital, London
}

Amyloid in the pulmonary tissues may be part of systemic amyloidosis or alternatively may be of a localised form limited entirely to the lower respiratory tract. Amyloid localised to the lower respiratory tract, first described by Lesser,' is relatively rare. Several forms, including endobronchial and parenchymal forms, are now recognised. We have recently encountered a patient with massive hilar lymphadenopathy and a large solitary pulmonary amyloid tumour that was unique because of the anatomical sites that were affected.

\section{Case report}

A 59-year-old Greek office worker was investigated in September 1980 after episodes of dull anterior chest pain. Chest radiographs, computed tomography, and needle aspiration suggested a malignant lesion in the right upper lobe with mediastinal node enlargement. A radiograph of his chest in 1976 had been normal.

When he was seen at the Brompton Hospital in November 1980 he had no symptoms except for an occasional dry cough. He smoked 15 cigarettes daily and previous illnesses included brucellosis, successfully treated in 1953, and a duodenal ulcer in 1978. Physical examination showed nothing abnormal except for reduced breath sounds in the right upper zone anteriorly. There was no evidence of visceromegaly. Spirometry gave values within normal limits and microscopy of urine, a full blood count, protein electrophoresis, and tests of renal and hepatic function all gave normal results.

Chest radiographs showed a mass $10 \times 5 \mathrm{~cm}$ in the right hilum and right upper lobe, suggestive of carcinoma with nodal metastases (fig 1). Fibreoptic bronchoscopy showed an obvious "tumour" protruding from the right-upperlobe bronchus. Multiple biopsy specimens showed amyloid. At operation in February 1981 a firm mass was found in the hilum of the right upper lobe and there was enlargement of the hilar and carinal nodes. The mass was explored and was found to contain yellow waxy material. The right-upper-lobe bronchus was affected and friable debris lay within its lumen. Right upper lobectomy was performed and blunt dissection of the affected nodes was carried out.

Pathological examination of the resected specimen showed the hilar mass to measure $7 \times 5 \times 3 \mathrm{~cm}$ and the excised lymph nodes $7 \times 4 \times 4 \mathrm{~cm}$. Both the mass and the excised lymph nodes consisted of a friable waxy material

Address for reprint requests: Dr PJ Thompson, Cardiothoracic Institute, Brompton Hospital, Fulham Road, London SW3 6HP.

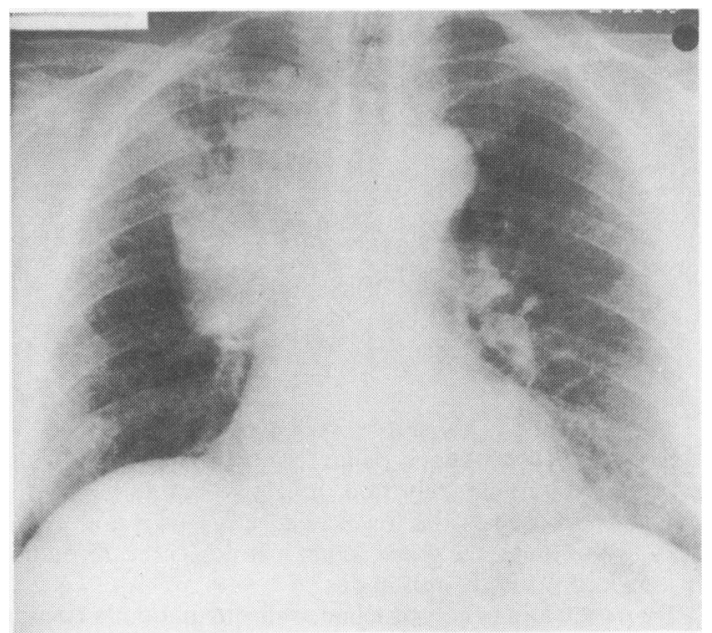

Fig 1 Chest radiograph showing right hilar mass of amyloid tumour.

and sections of both showed amorphous eosinophilic material surrounded by foreign-body-type giant cells, lymphocytes, and plasma cells (fig 2). Congo red stains were positive and with polarised light showed green birefringence. Electron microscopy showed abundant intertwining fibrils $8 \mathrm{~nm}$ thick. All these features are characteristic of amyloid.

\section{Discussion}

This case is unusual in that the large solitary amyloid tumour simultaneously affected the peripheral lung tissue and bronchus, protruded into the bronchial lumen, and was associated with massive infiltration of the draining hilar lymph nodes.

We have not been able to find any previous case reports of one amyloid mass simultaneously affecting the bronchi and pulmonary parenchyma. In this patient the amyloid tumour is likely to have originated in the peripheral lung and then enlarged to penetrate into the bronchial lumen. We cannot entirely exclude a bronchial origin; but there are only three previously reported cases of a large amyloid mass located near the hilum and these masses were situated in peripheral lung tissue..$^{2-4}$ In only one of these had the lesion extended as far as the outer walls of the right main bronchus. We are unaware of any reports of an endobronchial amyloid tumour extending radially beyond 


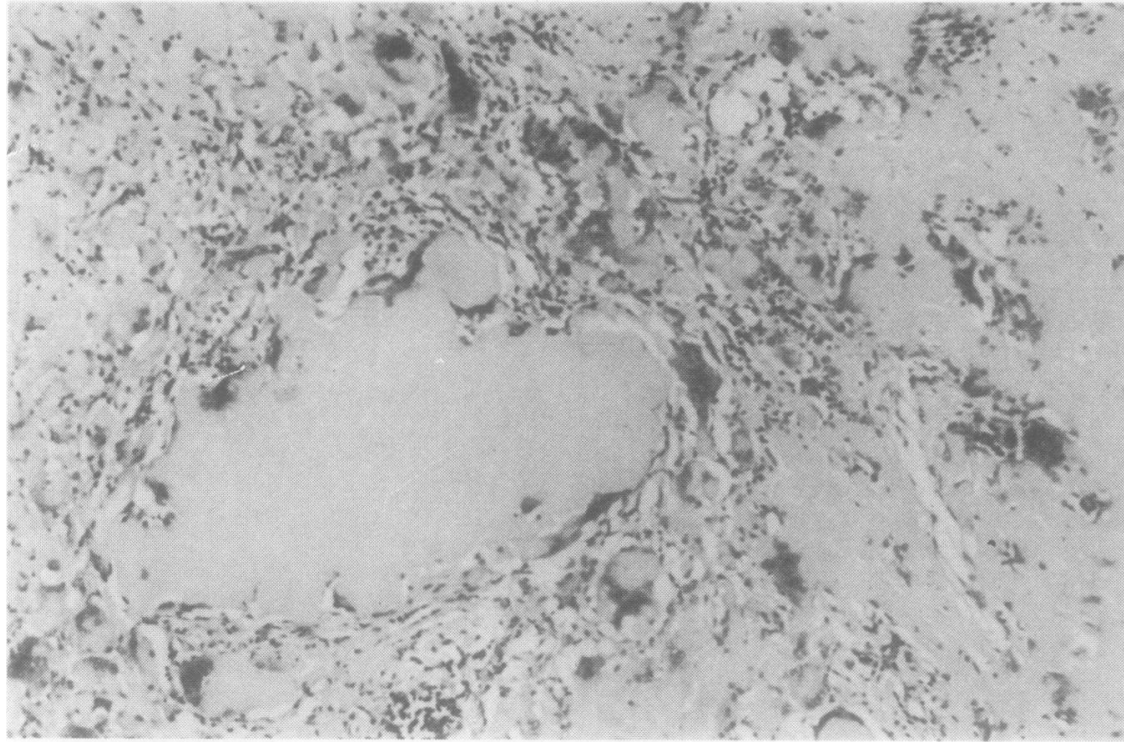

Fig 2 Amorphous amyloid material infiltrated by lymphocytes, plasma cells, and giant cells. (Haematoxylin and eosin, $\times 85$.)

the bronchial cartilages. Hilar lymphadenopathy is also rare, having been reported in only six patients with amyloid localised to the lower respiratory tract; $;^{5-10}$ and in only two of these was there actual histological confirmation of amyloid in the lymph nodes. ${ }^{79}$

By penetrating the bronchial wall our patient's tumour resembled a malignant growth when viewed through the bronchoscope. The massive enlargement of hilar lymph nodes also suggested carcinoma, but bronchoscopic biopsy provided the correct diagnosis. The affected lobe was not functioning and infection distal to the tumour appeared inevitable. Surgical resection offered the prospect of longterm relief and our patient remains free of disease and symptoms more than one year later. A diagnosis of pulmonary amyloid should be considered in the differential diagnosis of carcinoma of the lung, and surgical resection is often needed to obtain a definitive diagnosis as well as a cure.

We would like to thank Dr $J$ Collins for performing the fibreoptic bronchoscopy and $\mathrm{Mr} \mathbf{M}$ Paneth and $\mathbf{M r} \mathrm{A}$ Wood for permission to publish the surgical details of the case.

\section{References}

' Lesser A. Ein Fall von Enchondroma osteiodes mixtu角

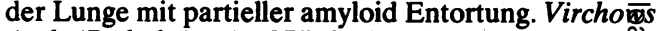
Arch (Pathol Anat) 1877;69:404-8.

${ }^{2}$ Weismann RE, Clagett OT, MacDonald JR. Amylogid disease of the lung treated by pneumonectomy. Thorac Surg 1947;16:269-81.

${ }^{3}$ Haynes AL, Clagget OT, MacDonald JR. Tumour forming amyloidosis of the lung. Surgery 1948;24:120-

${ }^{4}$ Hayes WT, Bernhardt H. Solitary amyloid mass of the lung. Cancer 1969;24:820-5.

${ }^{5}$ Noring O, Paaby H. Diffuse amyloidosis in the lower passages. Acta Pathol Microbiol Scand 1953;31: 470-5.

' Schmidt HW, MacDonald JR, Clagget OT. Amyloidd tumours of the lower part of the respiratory tract and mediastinum. Ann Otol Rhinol Laryngol 1953;68: 880-93.

${ }^{7}$ Meyer O. Uber lokales tumorartiges Amyloid in degn Lungen. Frankf Z Pathol 1911;8:304-18.

${ }^{8}$ D'arrigo S. L'amilodosi neoplastiforme de polmong. Arch Sci Med 1945;80:53-75.

9 Schuller H, Bolin H, Linder E, Stenram U. Tumaür forming amyloidosis of the lower respiratory systefrn. Chest 1962;42:58-67.

${ }^{10}$ Brown J. Primary amyloidosis. Clin Radie 1964;15:358-67. 